XX Міжнародний симпозіум «Методи дискретних особливостей в задачах математичної фізики/Discrete Singularities Methods in Mathematical Physics»,

УДК 321.311

MSC 93A30

\title{
Hydraulic Models in the Problems of Thermal Power Plant Auxiliary Energy Efficiency Improvement
}

\author{
V. Vanin, M. Kruhol \\ National Technical University "Kharkiv Polytechnic Institute", Kharkiv, Ukraine \\ E-mail:vvaplb5256@gmail.com,kruhgol@gmail.com
}

The work is devoted to the study of thermal power plants auxiliary energy efficiency. The main mechanisms in the auxiliary systems are centrifugal mechanisms that work in complex hydraulic networks with variable productivity. The main ways to adjust the parameters of the centrifugal mechanisms are to change the speed of rotor rotation, change the guide vane angle and throttle. The operation mode of a complex hydraulic network which includes a group of centrifugal mechanisms with a mixed connection scheme is analyzed. The system of equations which characterize the hydraulic system has been obtained on the basis of Kirchhoff's laws. The centrifugal mechanisms' operating characteristics are given by approximation dependences obtained with the method of least squares and similarity laws. To analyze efficiency of different methods of centrifugal mechanisms parameters regulation, optimal control problems were set and solved. The constraints for the problems are a system of equations that describe the hydraulic system operation and technical constraints that depend on the control method. Through solving the problems, values of the optimal parameters and weighted average efficiency of the group mechanisms were obtained. Studies have shown that the most effective way to regulate the centrifugal mechanisms parameters is to use an individual frequency drive, the least effective is to use only changing angle of centrifugal mechanism's guide vane. Utilization of group control is highly efficient and not inferior to individual frequency drive. However, this statement is correct under condition of the operating characteristics agreement with the centrifugal mechanisms' operating modes similarity.

Key words: optimal control, centrifugal mechanisms, variable frequency drive, thermal power plant auxiliaries.

\section{Гідравлічні моделі в задачах дослідження енергоефективності систем власних потреб ТЕС}

\section{В. Ванін, М. Кругол}

Національний технічний університет «Харківський політехнічний інститут», Харків, Україна

E-mail: vvaplb5256@gmail.com,kruhgol@gmail.com

Робота присвячена дослідженню енергоефективності систем власних потреб теплових електричних станцій. Основними механізмами в системах власних потреб є відцентрові механізми, які працюють в складних гідравлічних мережах зі змінною продуктивністю. Основними способами регулювання параметрів відцентрових механізмів є зміна швидкості обертання робочого колеса, зміна кута відкриття направляючого апарату та дроселювання. В роботі проводиться аналіз режиму роботи складної гідравлічної мережі в яку включена група відцентрових механізмів зі замішаною схемою з'єднання. На основі законів Кірхгофа була отримана система рівнянь, що характеризує стан гідравлічної мережі. Робочі характеристики відцентрових механізмів групи задані апроксимаційними залежностями, що були отримані за допомогою методу найменших квадратів та законів подібності. Для аналізу ефективності різних способів регулювання параметрів відцентрових механізмів групи були поставлені й вирішені задачі знаходження оптимальних параметрів керування механізмами групи. Обмеженнями для таких задач виступили система рівнянь, що

(с) Ванін В.А., Кругол М.М., 2021 


\begin{abstract}
описує функціонування системи, технічні обмеження щодо значень параметрів керування та додаткові обмеження, які залежать від способу регулювання. При вирішенні таких задач були отримані значення оптимальних параметрів та середньозважених ККД механізмів групи. Дослідження показали, що найбільш ефективним способом регулювання параметрів відцентрового механізму є використання індивідуального частотного приводу, найменш ефективним - використання лише зміни кута відкриття направляючого апарату відцентрового механізму. Використання групового регулювання має високу ефективність, та майже не уступає індивідуальному частотному приводу. Проте це твердження $є$ коректним при схожості робочих характеристик та режимів роботи відцентрових механізмів групи.
\end{abstract}

Ключові слова: оптимальне керування, відцентрові механізми, частотнорегульований привід, системи власних потреб теплових електричних станцій.

\title{
1. Вступ
}

Для забезпечення роботи основних агрегатів теплових електричних станцій в гідравлічних системах забезпечення власних потреб використовуються відцентрові механізми - насоси та вентилятори. Дані механізми є основними споживачами електричної енергії на теплових електричних станціях. Регулювання режимів їх роботи проводиться за допомогою зміни швидкості обертання робочого колеса, дроселювання та зміною кута відкриття направляючого апарату. Найбільш розповсюджений спосіб регулювання швидкості обертання робочого колеса - зміна частоти живильної напруги асинхронного електроприводу за допомогою використання перетворювачів частоти [1].

Дослідження режимів роботи таких гідравлічних мереж має значний інтерес, що полягає у визначенні найбільш ефективних параметрів керування відцентровими механізмами. Аналіз режимів роботи та способів регулювання відцентровими механізмами дає змогу отримати методику визначення складу груп механізмів 3 метою впровадження групового частотно-регулюваного приводу та досягти значної економії електричної енергії.

В даній роботі проводиться аналіз ефективності різних способів регулювання параметрів відцентрових механізмів.

Теплова електрична станція - є складним технічним об'єктом. Для забезпечення iï надійної та економічної роботи використовуються складні гідравлічні мережі паропроводи, повітропроводи, водоводи та інші. Для забезпечення перекачування робочого середовища використовуються насоси, вентилятори та компресори.

Прикладом складної гідравлічної мережі є газо-повітряний тракт котла (рис. 1). Для закачування повітря використовується пара дуттьових вентиляторі а для відкачки відпрацьованих газів - пара димососів.

\section{2. Математична модель функціонування системи}

Розглянемо гідравлічну мережу, схема якої показана на рис. 2, функціонування якої забезпечують три відцентрові механізми. Стан відцентрових механізмів визначається напором який вони розвивають $-H$, продуктивністю - $Q$, та параметрами керування - кутом відкриття направляючого апарату $-\alpha$, та частотою живильної напруги $-f$. Напірні характеристики даних механізмів відтворені у вигляді апроксимуючих виразів даних чисельних та експериментальних досліджень реальних серійних механізмів $[1,2]$. 
XX Міжнародний симпозіум «Методи дискретних особливостей в задачах математичної фізики/Discrete Singularities Methods in Mathematical Physics»,

\section{МДОЗМФ/DSMMPh-2021}

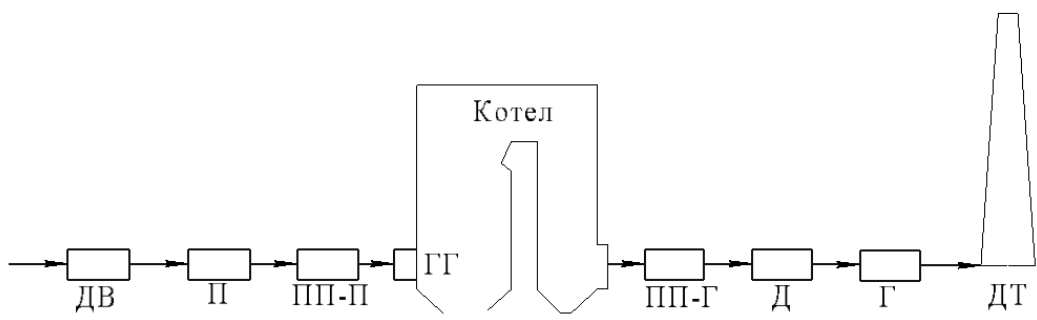

Рис. 1 - Газо-повітряний тракт парового енергетичного котла

ДВ - дуттьовий вентилятор; П - повітряпровід; ПП-П - повітряпідігрівач (повітряна сторона); ГГ - гадова горілка; ПП-Г - повітряпідігрівач (газова сторона); Д - димосос; Г газопровід; ДТ - димова труба.

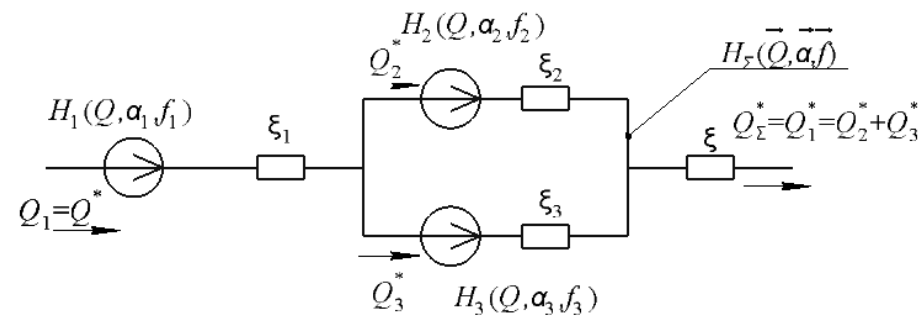

Рис. 2 - Еквівалентна схема гідравлічної мережі.

Система рівнянь, що описує функціонування даної гідравлічної мережі матиме вигляд

$$
\left\{\begin{array}{l}
H_{1}\left(\alpha_{1}, f_{1}, Q_{1}\right)-\xi_{1} Q_{1}^{2}+H_{2}\left(\alpha_{2}, f_{2}, Q_{2}\right)-\xi_{2} Q_{2}{ }^{2}=\xi Q_{1}{ }^{2} \\
H_{1}\left(\alpha_{1}, f_{1}, Q_{1}\right)-\xi_{1} Q_{1}^{2}+H_{3}\left(\alpha_{3}, f_{3}, Q_{3}\right)-\xi_{3} Q_{3}{ }^{2}=\xi Q_{1}{ }^{2} . \\
Q_{1}-Q_{2}-Q_{3}=0
\end{array}\right.
$$

Система (1) побудована за допомогою законів Кірхгофа [3].

Для оцінки ефективності групи відцентрових механізмів скористаємося середньозваженим ККД при $\mathrm{N}=3$

$$
\eta(\vec{f}, \vec{\alpha}, \vec{Q})=\frac{\sum_{i=1}^{N} P_{i} \eta_{i}\left(\alpha_{i}(f), Q_{i}, f\right)}{\sum_{i=1}^{N} P_{i}},
$$

де потужності визначається так $P_{i}=\frac{Q_{i} \rho g H_{i}}{1000 \eta_{\mathrm{i}}}$. Можливі і інші показники енергоефективності механізмів в розгалужених мережах.

\section{3. Аналіз способів регулювання відцентрових механізмів}

В системі обмежень (1) задані гідравлічні опори $\xi, \xi_{1}, \xi_{2}, \xi_{3}$ та необхідна продуктивність $Q_{1}$. Можливо постановка задачі де загальна продуктивність визначається разом із іншими оптимальними параметрами керування.

Систему рівнянь (1) перепишемо у вигляді

$$
\vec{\Psi}(\vec{f}, \vec{\alpha}, \vec{Q})=\vec{\Psi}\left(\alpha_{1}, \alpha_{2}, \alpha_{3}, f_{1}, f_{2}, f_{3}, Q_{1}, Q_{2}, Q_{3}\right)=0
$$


Тоді для максимізації ККД (2) при умові (1) необхідно знайти параметри керування відцентровими механізмами та розподілення продуктивностей між другим та третім механізмами. Розглянемо декілька задач знаходження оптимальних параметрів керування при різних способах регулювання продуктивностей відцентрових механізмів групи.

Загальний вигляд задачі буде відповідати найбільш складному випадку, коли використовуються індивідуальні частотні приводи, тобто регулювання кожного 3 механізмів проводиться двома способами - зміною частоти живильної напруги та кута відкриття направляючого апарата. Поставимо задачу знаходження оптимальних параметрів керування для даного випадку

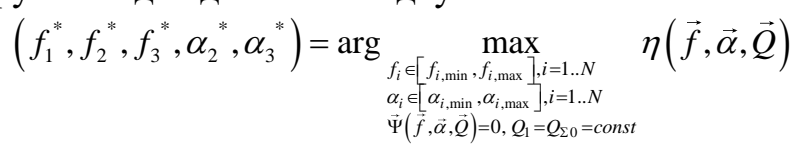

У випадку групового регулювання частоти живильної напруги - будемо використовувати один спільний перетворювач частоти, від якого живляться всі відцентрові механізми групи. Тоді введемо додаткове обмеження - рівність частот живильної напруги і задача знаходження оптимальних параметрів керування матиме вигляд

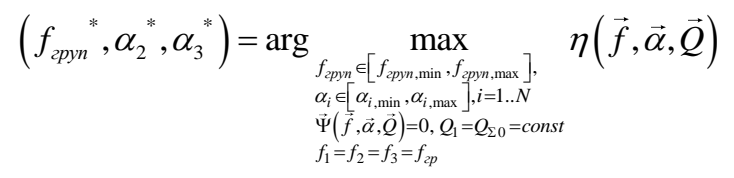

Наступний клас задач, що виникає при аналізі режимів роботи відцентрових механізмів - це використання індивідуального частотного приводу на одному 3 механізмів групи, інші механізми живляться від електричної мережі з постійною частотою 50Гц. Запишемо задачу знаходження оптимальних параметрів керування коли для приводу першого відцентрового механізму застосовується частотний привод.

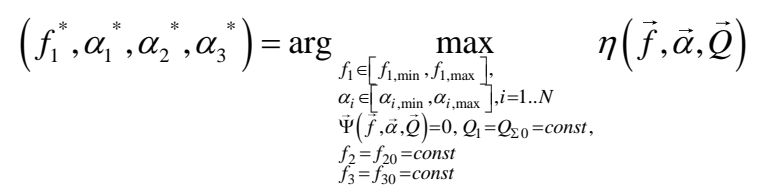

Остання задача, що виникає це знаходження оптимальних параметрів керування в випадку, коли перетворювачі частоти не застосовуються. В такому випадку всі частоти живильної напруги задається постійними та рівними частоті живильної мережі, а задача знаходження оптимальних параметрів керування матиме вигляд

$$
\left(\alpha_{2}{ }^{*}, \alpha_{3}{ }^{*}\right)=\arg \max _{\substack{\alpha_{i} \in\left[\alpha_{i, \min }, \alpha_{i, \max }\right], i=1 . . N \\ \vec{\Psi}(\vec{f}, \vec{\alpha}, \vec{Q})=0 \\ Q_{1}=Q_{\Sigma 0}=\text { const } \\ f_{1}=f_{2}=f_{3}=f_{0}=\text { const }}} \eta(\vec{f}, \vec{\alpha}, \vec{Q})
$$

\section{4. Результати математичного моделювання}

Вирішимо задачі (5)-(8) при заданій продуктивності $Q_{\Sigma 0}=100$ тис. м $3 /$ год. Приймемо значення еквівалентних гідравлічних опорів рівними: $\xi=0,04$, $\xi_{1}=0,001, \xi_{2}=\xi_{3}=0,002$. Частота живильної напруги електричної мережі становить 50 Гц. Характеристики механізмів представимо у вигляді 
XX Міжнародний симпозіум «Методи дискретних особливостей в задачах математичної фізики/Discrete Singularities Methods in Mathematical Physics»,

МДОЗМФ/DSMМPh-2021

$$
\begin{gathered}
H_{Ц Р-40}(Q, \alpha, f)=0,12305 f^{2}+0,00247 \alpha f^{2}+0.03568 \cdot 10^{-3} Q f- \\
-0,00111 \cdot 10^{-3} \alpha Q f-0,00003 \alpha^{2} f^{2}-0,01495 \cdot 10^{-6} Q^{2} \\
\eta_{Ц P-40}(Q, \alpha, f)=5,29717+1,85334 \alpha+75,88335 \cdot 10^{-3} Q f^{-1}- \\
-0,78447 \cdot 10^{-3} \alpha Q f^{-1}-0,01822 \alpha^{2}-17,5961 \cdot 10^{-6} Q^{2} f^{-2} \cdot \\
H_{\text {ВДН-17-3}}(Q, \alpha, f)=0,10809 f^{2}+0,00134 \alpha f^{2}+0,0491 \cdot 10^{-3} Q f- \\
-0,0013 \cdot 10^{-3} \alpha Q f-0,00002 \alpha^{2} f^{2}-0,0432 \cdot 10^{-6} Q^{2} \\
\eta_{\text {ВДН-17-3 }}(Q, \alpha, f)=11,08442+1,28361 \alpha+136,2035 \cdot 10^{-3} Q f^{-1}- \\
-1,18969 \cdot 10^{-3} \alpha Q f^{-1}-0,01116 \alpha^{2}-60,485 \cdot 10^{-6} Q^{2} f^{-2} \\
H_{\text {ВДН-15-3 }}(Q, \alpha, f)=0,078196 f^{2}+0,001019 \alpha f^{2}+0,071504 \cdot 10^{-3} Q f- \\
-0,001416 \cdot 10^{-3} \alpha Q f-0,000013 \alpha^{2} f^{2}-0,082320 \cdot 10^{-6} Q^{2} \\
\eta_{\text {вдн-15-3 }}(Q, \alpha, f)=30,194970+0,727972 \alpha+144,643992 \cdot 10^{-3} Q f^{-1}- \\
-0,835551 \cdot 10^{-3} \alpha Q f^{-1}-0,008259 \alpha^{2}-97,650592 \cdot 10^{-6} Q^{2} f^{-2}
\end{gathered} .
$$

\begin{tabular}{|c|c|c|c|c|c|c|c|c|c|c|c|c|}
\hline & \multicolumn{3}{|c|}{ Задача (4) } & \multicolumn{3}{|c|}{ Задача (5) } & \multicolumn{3}{|c|}{ Задача (6) } & \multicolumn{3}{|c|}{ Задача (7) } \\
\hline & 1 & 2 & 3 & 1 & 2 & 3 & 1 & 2 & 3 & 1 & 2 & 3 \\
\hline $\begin{array}{c}\alpha, \\
\text { град }\end{array}$ & 9,42 & 5,08 & 5,08 & 12,72 & 4,88 & 4,88 & 5,47 & 66,18 & 6,19 & 36,62 & 78,87 & 28,79 \\
\hline $\mathrm{f}, \Gamma_{ц}$ & 45 & 40 & 40 & 43 & 43 & 43 & 41 & 50 & 50 & 50 & 50 & 50 \\
\hline $\begin{array}{c}\mathrm{Q}, \\
\text { тис. } \\
\mathrm{M}^{3} / \text { год }\end{array}$ & 100 & 50 & 50 & 100 & 50 & 50 & 100 & 30 & 70 & 100 & 30 & 70 \\
\hline $\begin{array}{c}\mathrm{H}, \\
\text { даПа }\end{array}$ & 255 & 160 & 160 & 220 & 195 & 195 & 200 & 211,8 & 219,8 & 260 & 151,8 & 159,8 \\
\hline$\eta, \%$ & 86,45 & 85,87 & 85,87 & 84,03 & 87,24 & 87,24 & 84,83 & 59,95 & 80,59 & 72,65 & 46,64 & 63,44 \\
\hline$\eta_{\mathrm{cp}}, \%$ & & 86,23 & & & 85,51 & & & 78,33 & & & 66,06 & \\
\hline
\end{tabular}

\begin{tabular}{|c|c|c|c|c|c|c|c|c|c|c|c|c|}
\hline & \multicolumn{3}{|c|}{ Задача (4) } & \multicolumn{3}{|c|}{ Задача (5) } & \multicolumn{3}{|c|}{ Задача (6) } & \multicolumn{3}{|c|}{ Задача (7) } \\
\hline & 1 & 2 & 3 & 1 & 2 & 3 & 1 & 2 & 3 & 1 & 2 & 3 \\
\hline $\begin{array}{c}\alpha, \\
\text { град }\end{array}$ & 2,19 & 17,98 & 3,69 & 2,19 & 1,40 & 36,85 & 5,47 & 6,19 & 30,85 & 36,63 & 46,13 & 32,44 \\
\hline $\mathrm{f}, \Gamma ц$ & 45 & 44 & 45 & 45 & 45 & 45 & 41 & 50 & 50 & 50 & 50 & 50 \\
\hline $\begin{array}{l}\text { Q, тис. } \\
\mathrm{M}^{3} / \text { год }\end{array}$ & 100 & 60 & 40 & 100 & 70 & 30 & 100 & 70 & 30 & 100 & 58 & 42 \\
\hline $\begin{array}{c}\mathrm{H}, \\
\text { даПа }\end{array}$ & 260 & 157,20 & 153,2 & 260 & 159,80 & 151,80 & 200 & 219,8 & 211,8 & 260 & 156,73 & 153,53 \\
\hline$\eta, \%$ & 87,19 & 75,08 & 81,44 & 87,19 & 76,35 & 78,31 & 84,83 & 80,51 & 80,96 & 72,65 & 59,82 & 74,95 \\
\hline$\eta_{\mathrm{cp}}, \%$ & \multicolumn{3}{|c|}{83,27} & \multicolumn{3}{|c|}{83,00} & \multicolumn{3}{|c|}{82,59} & \multicolumn{3}{|c|}{69.71} \\
\hline
\end{tabular}

Порівняємо два випадки - коли відцентрові механізми 2 та 3 однакові (використовуються 2 вентилятори ВДН-17-3, результати розрахунку знесені до таблиці 1) та різні (використовуються механізми ВДН-17-3 та ВДН-15-3 результати розрахунків знесені до таблиці 2).

Таблиця 1 - Результати моделювання для випадку однакових механізмів 2 та 3.

Таблиця 2 - Результати моделювання для випадку різних механізмів 2 та 3. 
Як видно з результатів розрахунків найбільш ефективним способом регулювання параметрів відцентрових механізмів є індивідуальний частотний привід. Це пояснюється тим, що в даному випадку можна вийти на такий режим роботи при якому кожен 3 відцентрових механізмів працюватиме на індивідуальних оптимальних параметрах 3 найвищим ККД. Проте груповий частотний привід майже не уступає по ефективності індивідуальному. Найменшу ефективність має режим управління зміною кута відкриття направляючого апарату. Використання індивідуального частотного перетворювача для приводу найбільш потужного механізму значно підвищує ефективність роботи групи механізмів в порівнянні з використанням лише направляючого апарату. При використанні різних напірних характеристик у паралельно працюючих відцентрових механізмів 2 та 3 ефективность регулювання зроста., це пояснюється тим, що розподілення продуктивностей між ними дозволяє їх роботу в зоні індивідуальної високої ефективності.

В розгалужених гідравлічних мережах для котлів ТЕС знаходяться відцентрові механізми із різними напірними характеристиками і різним опором трубопроводів для них. Має практичне значення вплив такої неоднорідності складної мережі на оптимальний ККД. Змінний добовий характер необхідної продуктивності приводить до необхідності дослідження нестаціонарного управління для таких систем.

\section{ЛІТЕРАТУРА}

1. Kruhol M., Vanin V., Lasurenko O. Assessment of group regulation feasibility in thermal power plant auxiliaries capacity control. Eastern-European Journal of Enterprise Technologies. 2020. Vol. 6 (8 (108)). P. 45-53.

2. Ванін В.А., Кругол М.М., Лазуренко О.П. Математичні моделі та результати дослідження гідравлічних систем ТЕС. Праці 7-ої Міжнародній конференції «Комп'ютерне моделювання в наукоємних технологіях (КМНТ-2021), 21-23 квітня Харків, ХНУ ім. В.Н.Каразіна. 2021.

3. Ванін В.А., Кругол М.М., Лазуренко О.П. Математичне моделювання одногрупового газогідравлічного тракту допоміжних механізмів парового котла теплової електричної станції. Вісник НТУ «ХПI». Сер.: Математичне моделювання в техніиі та технологіяx. 2020. № 1. С. 3-14.

Надійшла 20.05.2021.

\section{Гидравлические модели в задачах исследования энергоэффек- тивности систем собственных нужд ТЭС \\ В. Ванин, Н. Кругол}

Национальный технический университет «Харьковский политехнический институт», Харьков, Украина

E-mail:vvaplb5256@gmail.com,kruhgol@gmail.com

Работа посвящена исследованию энергоэффективности систем собственных нужд тепловых электрических станций. Основными механизмами в системах собственных нужд есть центробежные механизмы, которые работают в сложных гидравлических сетях с переменной производительностью. Основными способами регулирования параметров центробежных механизмов есть изменение скорости вращения рабочего колеса, изменение угла открытия направляющего аппарата и дросселирование. В работе проводится анализ режима работы гидравлической сети, в которую 
XX Міжнародний симпозіум «Методи дискретних особливостей в задачах математичної фізики/Discrete Singularities Methods in Mathematical Physics»,

\section{МДОЗМФ/DSMМPh-2021}

включена группа центробежных механизмов по смешанной схеме соединения. На основании законов Кирхгофа была получена система уравнений, которая характеризует состояние гидравлической сети. Рабочие характеристики центробежных механизмов группы заданы апроксимационными зависимостями, полученные с помощью метода наименьших квадратов и законов подобности. Для анализа эффективности разных способов регулирования центробежных механизмов были поставлены и решены задачи нахождения оптимальных параметров управления механизмами группы. Ограничениями для таких задач выступили система уравнений, которая характеризует систему, технические ограничения параметров управления и дополнительные ограничения, которые зависят от способа регулирования. При решении таких задач были получены значения оптимальных параметров управления и средневзвешенный КПД механизмов группы. Исследования показали, что наиболее эффективным способом регулирования параметров центробежного механизма есть использование индивидуального частотного привода, наименее эффективным - использование лишь изменения угла открытия направляющего аппарата центробежного механизма. Использование группового регулирования имеет высокую эффективность, и практически не уступает индивидуальному частотному приводу. Данные утверждения являются корректными при близости рабочих характеристик и режимов работы центробежных механизмов группы.

Ключевые слова: оптимальное управление, центробежные механизмы, частотнорегулируемый привод, системы собственных нужд тепловых электрических станций. 